\title{
First Nations data sovereignty in Canada
}

\author{
The First Nations Information Governance Centre \\ First Nations Information Governance Centre, 180 Elgin Street, Suite 1200, Ottawa, ON, Canada \\ Tel.: +1 613733 1916; Fax: +1613231 7072; E-mail: info@fnigc.ca
}

\begin{abstract}
Drawing on historical and contemporary sources, this paper provides an overview of First Nations perspectives on efforts within the Canadian context to identify First Nations individuals, communities, and Nations in official statistics and other data and ongoing First Nations assertion of data sovereignty. Topics covered include: an overview of pre- and post-contact First Nations history and experiences with the Canadian government and researchers; an overview of the socio-demographic characteristics of the First Nations population in Canada; a description of the data and information contexts within which First Nations operate in Canada; an overview of the current definition(s) and understanding of First Nations data sovereignty; and an overview of efforts to assert First Nations Data Sovereignty in Canada, including the current work to advance these issues.
\end{abstract}

Keywords: Data sovereignty, Indigenous data governance, First Nations data, health data and data systems, OCAP ${ }^{\circledR}$, nationbased

\section{Introduction}

Drawing on historical and contemporary sources, this paper provides an overview of First Nations experiences with and perspectives on efforts within the Canadian context to identify First Nations individuals, communities, and Nations in official statistics and other data sources. Particular attention is given to First Nations-led efforts over the past 20 years to advance the assertion First Nations Data Sovereignty in Canada. Inuit and Métis approaches to official statistics are not covered in detail. Readers are encouraged to take a distinctions-based approach to understanding the broader Indigenous Canadian context, which is discussed in greater detail in Section 3.

\section{Historical First Nations context}

\subsection{Pre-contact}

First Nations people have occupied and used lands in what is now known as Canada for thousands of years prior to the arrival of Europeans, each possessing distinct cultural languages, histories, and traditional ways of life [1]. Some lived nomadic huntergatherer lifestyles, while others were agricultural so- cieties. Many First Nations societies were matriarchal, wherein women were highly revered as political leaders (often choosing male leaders), decisionmakers, and life-givers, and were central to the wellbeing of the family and tribe. This also meant that the family property, wealth, and clan all passed through the female line. Traditionally, gender roles were regarded as equally important, balanced, with both men and women working together in their respective duties to ensure the family and community remained intact. Although this may vary from nation to nation, men were primarily involved in hunting, warfare, crafting weapons, and building shelters, while women engaged in horticultural activities - harvesting plants and food, making crafts and clothing - and were the primary caregivers of children [2]. Both men and women were responsible for imparting valuable teachings to their children. Elders also played a vital role as advisors and educators of spiritual and cultural knowledge in the community.

Since time immemorial, First Nations people had the ability to determine all their needs and how to best meet those needs using the plants, herbs, animals, and the environment to survive, heal, and maintain balance. Their abilities and decisions were based on years of knowledge gained through observations, experiences, and information gathered from their surrounding envi- 
ronments. Thousands of years of relating to the land provided the occupants, as stewards, with the knowledge and ability to harness their knowledge and pass it down to succeeding generations. In this way, First Nations, as sophisticated societies with sophisticated governing structures, were engaged in research processes, policy-making, and knowledge sharing as part of their ethical responsibilities as stewards of the land [3].

\subsection{Post-contact}

As Europeans began settling in North America in the 1400s, including Canada, they relied heavily on First Nations for their knowledge and resources to survive the harsh climates and terrain. As independent Nations, First Nations created alliances with Europeans and played a significant role in trade and the economy, exploration routes, and strategic warfare. As European desires for increased land and control over trade grew, First Nations people were forced into smaller and smaller tracts of land, which was often away from settler communities, with limited or no access to the developments and inventions of the outside world [1,4,5]. The settlers and their governments saw First Nations people as a problem to be eradicated in order to further their vision of a new nation that expanded from east to west [4]. Over the next two centuries, conflicts arose over competing interests among the Europeans (Britain and France) and First Nations over political and military alliances, the fur trade, land and resources, and religious beliefs.

Following the end of the Seven Year War in 1763 (in which many First Nations fought as British allies), Great Britain claimed territory in North America and issued the Royal Proclamation of 1763, which gave recognition to First Nations' rights to land and title and laid the foundation for defining the future relationship between First Nations and the Crown, including a framework for negotiation of Indian treaties. In order to obtain the land needed for farming, the British Crown entered into treaties with Indigenous peoples during the 18th century. They also established an Indian Department that dealt specifically with matters related to First Nations, such as maintaining peaceful relations, securing land and resources, and protecting the interest of the British Crown. In the years that followed, there was a shift in the relationship between First Nations and the settlers. First Nations were progressively pressured into surrendering vast amounts of lands and territories, renouncing their traditional beliefs and way of life, and integrating into the European culture.
Section 91(24) of the Constitution Act, 1867 gave the federal government legislative authority and responsibility for "Indians, and Lands reserved for the Indians". Canada signed treaties with First Nations beginning in 1871 and continuing long after the turn of the century. Treaties have traditionally been drafted as agreements between nations. There are 11 numbered treaties in Canada, as well as other adhesions and treaties signed [6,7]. Many scholars [6,8-13] provide descriptions of colonization, extermination, and assimilation policies, including residential schools, the Sixties Scoop, and other tactics utilized by the federal government that were used to rid Canada of the so-called "Indian problem". ${ }^{1}$ The Sixties Scoop saw thousands of Indigenous children "scooped up" (i.e. taken without consent) from their families and communities between the 1950's and the 1980's by government childwelfare services, and placed with non-Indigenous foster homes and adoptive families, and even in different countries.

The term "Indian" is a misnomer that was applied to the original peoples of North America by European explorers when they first arrived as they believed they had landed in India. The Indian Act of 1876 is the federal legislation that allowed, and continues to allow, the Canadian government to control most aspects of Indian lives. Under this Act, "Indian" became the legal term to identify an individual who is considered a registered status, ${ }^{2}$ treaty status, or non-status Indian. It also defined how status was passed from generation to generation or terminated [13-15]. The Indian Act resulted in three categories of Indians which include: 1) status Indians who are legally entitled to be registered in the federal government's Indian Registration System; 2) Treaty Indians who are members of a community that signed a treaty with the Crown; and 3) non-Status Indians who are not legally entitled to be registered in the Indian Registration System. Other terms that have often been used interchangeably with "Indian" include: North American Indian, Native, and Native American. Today, the most commonly used contemporary term is First Nations, a term that was adopted by most First Nations leaders themselves, and can be seen as an act of self-determination. The Indian Act also

\footnotetext{
${ }^{1}$ Duncan Campbell Scott, as Deputy Superintendent of the Department of Indian Affairs, used this term in a letter to British Columbia Indian Agent General Major D. MacKay, in response to Dr. Peter Bryce's 1907 Report on Indian Schools of Manitoba and the Northwest Territories.

${ }^{2}$ The Indian Act specifies the conditions for an individual's entitlement to be registered as a status Indian.
} 
governs "Lands Reserved for Indians" and therefore created what is known as Indian reserves, which are dedicated tracts of land owned by the British Crown "for the use and benefit of a [Indian] band". Treaties between First Nations and the Crown were also negotiated and signed and this saw the transfer of large tracts of land in return for certain provisions and promises laid out in the respective treaty. Readers should also note that the terms "Aboriginal" (as found in the Constitution Act, 1982) and "Indigenous" are the collective nouns used to refer to First Nations, Inuit, and Métis peoples and should not be used in the Canadian context except to refer to these three distinct peoples collectively.

The dominant colonial government imposed patriarchy on First Nations societies and negatively influenced traditional gender roles, leadership structures, and governance - diminishing women's roles and reinforcing inequality between the sexes. Enfranchisement, the foundation of Canadian Indian policy, was the process by which Indians lost their registered Indian status and were assimilated into the dominant Canadian society. Those First Nations individuals who enlisted in the Canadian military, who enrolled in university, or who became priests, lost their Indian status and were "enfranchised", becoming so-called civilized Canadian citizens. The discriminatory treatment of Indian women and their descendants was also reinforced in the status provisions of the Indian Act. Status Indian women who married non-First Nation men lost their Indian status, including the ability to transfer status to their children. First Nations men marrying non-First Nation women could not only preserve Indian status but also saw their spouses gain Indian status, as well as their children. These provisions severed First Nations women and children from their culture, identity, and traditional lands.

Further discriminatory legislation and policies banned cultural ceremonies and practices, created reserves, outlawed or restricted the selling of produce or other resources from reserves, and forced children and youth to attend residential schools. The Pass System, an unlawful Canadian policy, ensured that First Nations people could not freely move off reserve without the written consent of the appointed government agent, known as an Indian agent $[7,16]$. The White Paper of 1969 was yet another attempt by the Canadian government to terminate the special legal relationship with First Nations and eliminate the Department of Indian Affairs. This policy was soundly rejected by First Nations leaders and communities across Canada as many believed that it would lead directly to assimilation and cultural genocide [17].

Aboriginal Peoples, regardless of status and residency, have a special constitutional relationship with the Crown, including existing Aboriginal and treaty rights, which is recognized and affirmed in section 35 of the Constitution Act, 1982. As described above, in this Act, "Aboriginal peoples of Canada" includes the Indian, Inuit, and Métis peoples of Canada. Following Canada's support of the United Nations Declaration on the Rights of Indigenous Peoples (UNDRIP) in 2010 , the federal and provincial governments, as well as many Aboriginal groups and organizations, have moved to support the use of the term Indigenous, rather than the term Aboriginal.

In 2015, Canada committed to a renewed nation-tonation relationship, based on the recognition of rights, respect, cooperation, and partnership with Indigenous peoples in Canada. In a statement by Prime Minister Justin Trudeau, Canada vowed to fully implementing the 94 Calls to Action of the Truth and Reconciliation Commission of Canada (TRC) to eliminate the socio-economic gaps and improve the well-being of Indigenous Peoples in Canada [18]. Canada further declared that the UNDRIP would be fully implemented into Canadian law, including Article 19 on requirements of states to obtain the free, prior and informed consent (FPIC) of Indigenous peoples on any decisions that would impact them. Although they have made many grand promises, some commentators have questioned Canada's true intentions. In a May 30, 2018, MacLean's article, Dr. Pamela Palmater stated that "it would be just one of the dizzying number of explicit promises that Trudeau would break by purchasing the Trans Mountain pipeline from Kinder Morgan for \$4.5 billion" [19]. Despite a recent Federal Court of Appeal decision to disallow Canada's Trans Mountain pipeline expansion project on the basis that Canada did not fulfill its duty to consult with affected First Nations, Canada has vowed to move forward on the pipeline [20]. In February 2018, Minister Trudeau announced that Canada would develop, in partnership with Indigenous Peoples, a transformative Recognition and Implementation of Rights Framework. Analysis done by the Yellowhead Institute reveals that "the Rights Framework expresses a clear and coherent set of goals, which aim to suppress Indigenous self-determination within Canadian Confederation" [21] and eliminate federal responsibility under the Indian Act.

Over the past century, First Nations have been continuously subjected to expensive litigation by different 
levels Canadian government to challenge and defend their inherent and constitutionally protected rights. Despite the myriad and complex challenges, First Nations in Canada remain unwavering in their aspirations and efforts to have their full rights as self-governing nations and original inhabitants of the land recognized and respected. First Nations rights transcend the reserve boundaries, the Indian Act, and government policy. Integral to these rights are concepts of data sovereignty and information governance. Further, there is a long history in Canada of First Nations peoples and communities being subjects of research, including unethical medical, health, and social research by academic and government researchers.

Much of the literature on First Nations peoples has been written from a colonial perspective resulting in a limited representation and oftentimes stereotypical and damaging depictions of First Nations peoples. For years, different types of research and research instruments have been conducted on First Nations in an attempt to better understand their experiences, health status, and their socio-economic and cultural environments. Although data can help identify priorities, set strategic goals, and support community planning, many First Nations communities have experienced their community's data being used for other purposes and not in their best interests or benefit. As the Alberta First Nations Information Governance Centre (AFNIGC) has noted, "[t]he content and purposes of data have historically been determined outside of First Nations communities, and the misuse of data has led to situations of misappropriation and broken trust" [22]. Further, data collection through government agencies has been used against communities to extract children from their families during the residential schools era and the '60's scoop: "Government agents knew of families and their children because those parents had shared information with government agents through registry programs, legal involvement, or other course of life activities" [22]. As a result of this deep communal and personal loss, the mistrust in the system resulted in the withdrawal from sharing personal information and engagement with government systems. The legacy of unethical research practices experienced by First Nations communities had led to their mistrust in research and information sharing with non-First Nations researchers, institutions, and governments. Increasingly, First Nations' citizens and leaders "acknowledge and act on the premise that information needs defending and protecting; just as we protect our lands, forest, animals and fish, we need to protect our data, which is an extremely valuable renewable resource" [23]. First Nations sovereignty over information and data is a crucial step toward changing the research paradigm, as well as achieving respective nations' self-governance aspirations and exercise of selfdetermination.

\section{The national First Nations picture}

In 2016, 1,673,785 people in Canada identified themselves as Aboriginal - making up 4.9 percent of the total population [24]. Of those, 977,230 (58.4 percent) were First Nations, 587,545 (35.1 percent) were Métis, and 65,025 (3.9 percent) were Inuit [24]. Widely dispersed across Canada, each Aboriginal group possesses diverse cultural heritages, histories, distinct languages, customs, and traditional lands.

In 2016, First Nations people accounted for 2.8 percent of the total population of Canada. Many First Nations belong to an Indian band, reside in a First Nations community (Indian reserve) or crown land, or live off-reserve in rural, remote or urban centre. Status First Nations account for three quarters $(744,855)$ of the population, while the remaining 232,375 (23.8 percent) were non-status [24]. The census data found that, among the status First Nations people, over half (55.8 percent, 415,629$)$ lived off-reserve, while the other 44.2 percent $(329,226)$ lived on-reserve. The majority (97.8 percent) of non-status First Nations lived off-reserve [24]. Figure 1 is a map that illustrates where First Nations communities are located in Canada, as well as shows their status symbolized as the Indian Act, the First Nations Land Management Act, or SelfGovernment [25].

According to the federal government there are currently 636 recognized Indian bands in Canada possessing more than 50 distinct languages [25]. The 2016 Canadian Census of Population showed that First Nations peoples are mainly concentrated in the western provinces, with over half living in British Columbia, Alberta, Saskatchewan, and Manitoba. Among the provinces, Ontario had the highest percentage (24.2 percent) of First Nations peoples, while 9.5 percent lived in Quebec, 7.5 percent in the Atlantic Provinces, and 2.1 percent in the territories [24]. Figure 2 is a map showing the distribution of the total Aboriginal population of each province or territory [26]. Readers should note the high percentage of unique languages in the province of British Columbia alone, as well as the diversity of geography in this and other regions. 


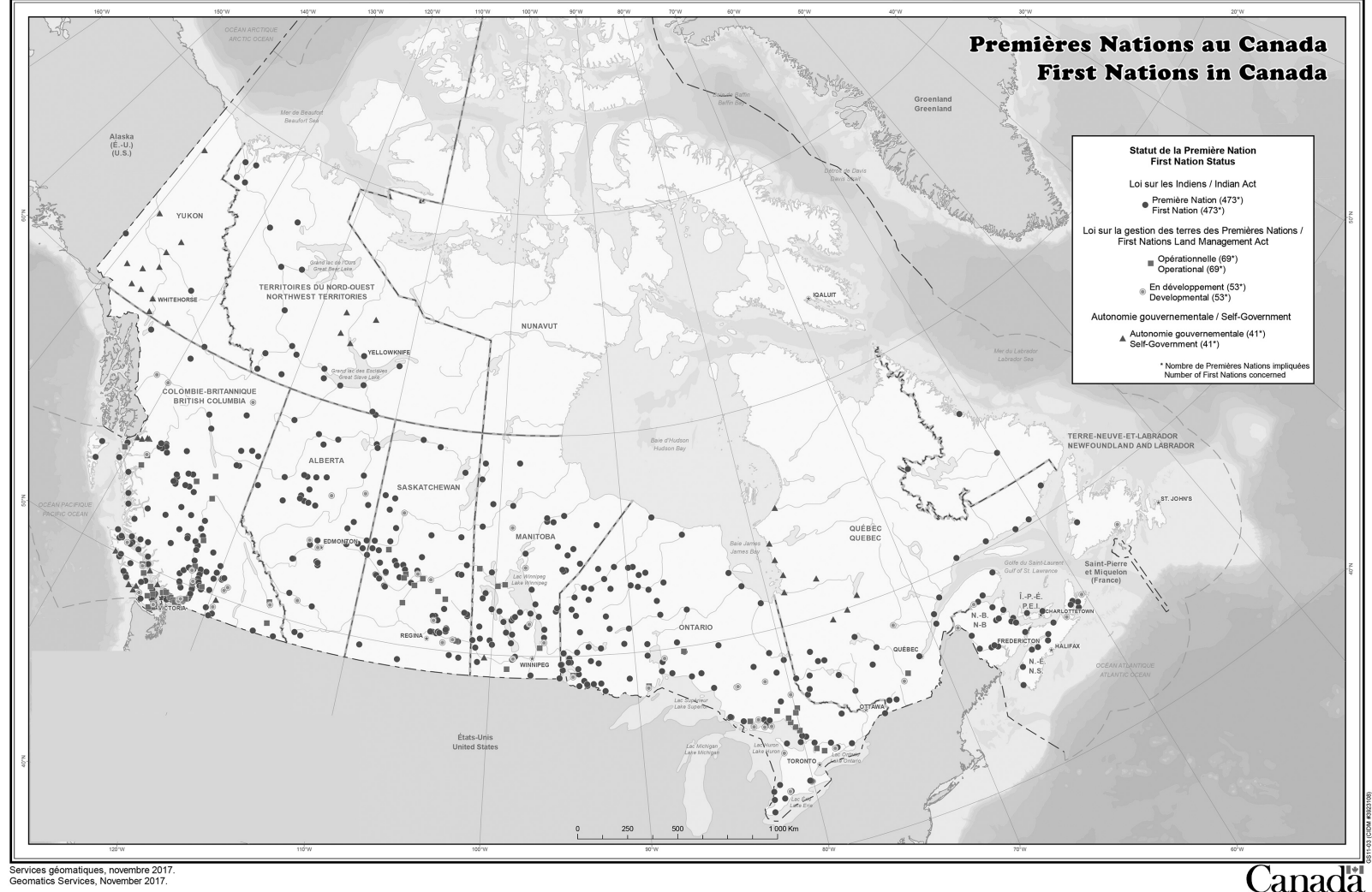

Fig. 1. First Nations in Canada. This map illustrates where First Nations communities are located in Canada, as well as shows First Nations status symbolized as the Indian Act, the First Nations Land Management Act or Self-Government. Source: Indigenous and Northern Affairs Canada, Geomatics Services, November 2017.

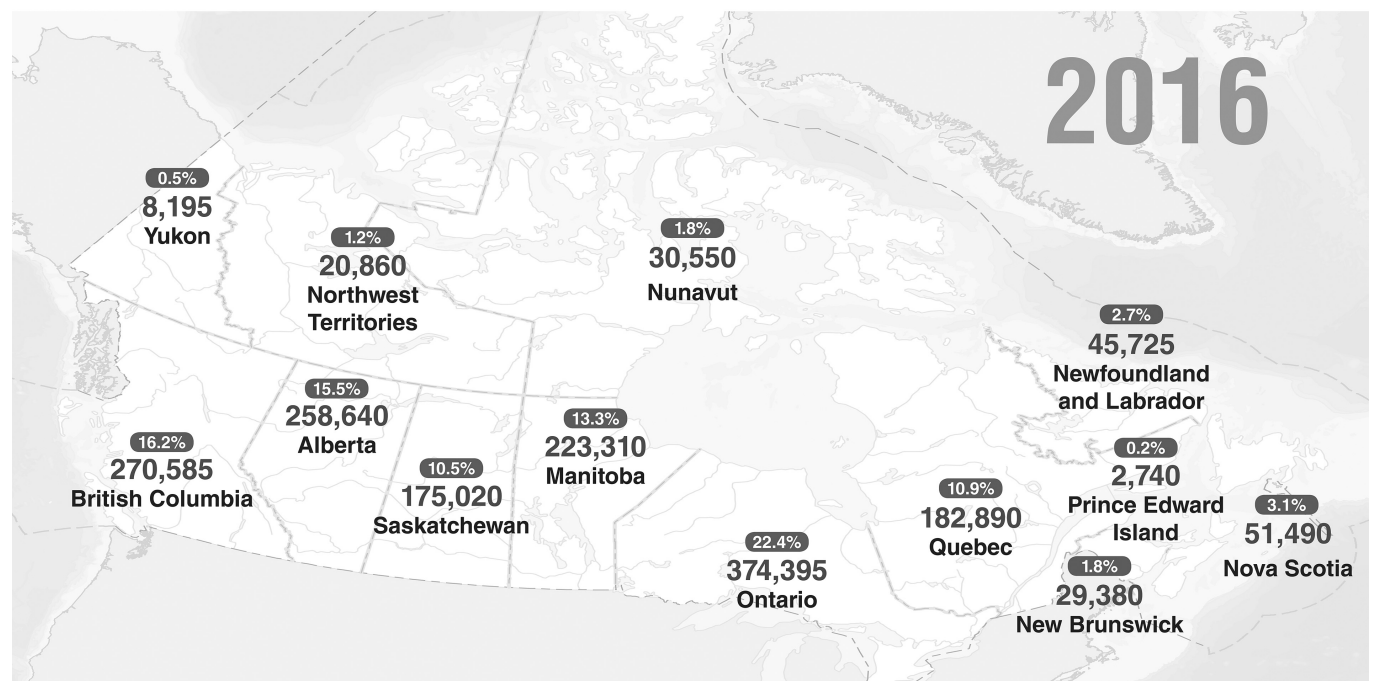

Fig. 2. Regional Aboriginal Population Proportions. This map shows the distribution of the total Aboriginal population $(\mathrm{N}=1,673,780)$ of each province or territory. Source: Statistics Canada, Census of Population, 2016. Indigenous Services Canada/Crown and Indigenous Relations and Northern Affairs Canada, Strategic Research and Statistics Directorate tabulations, 2018. 


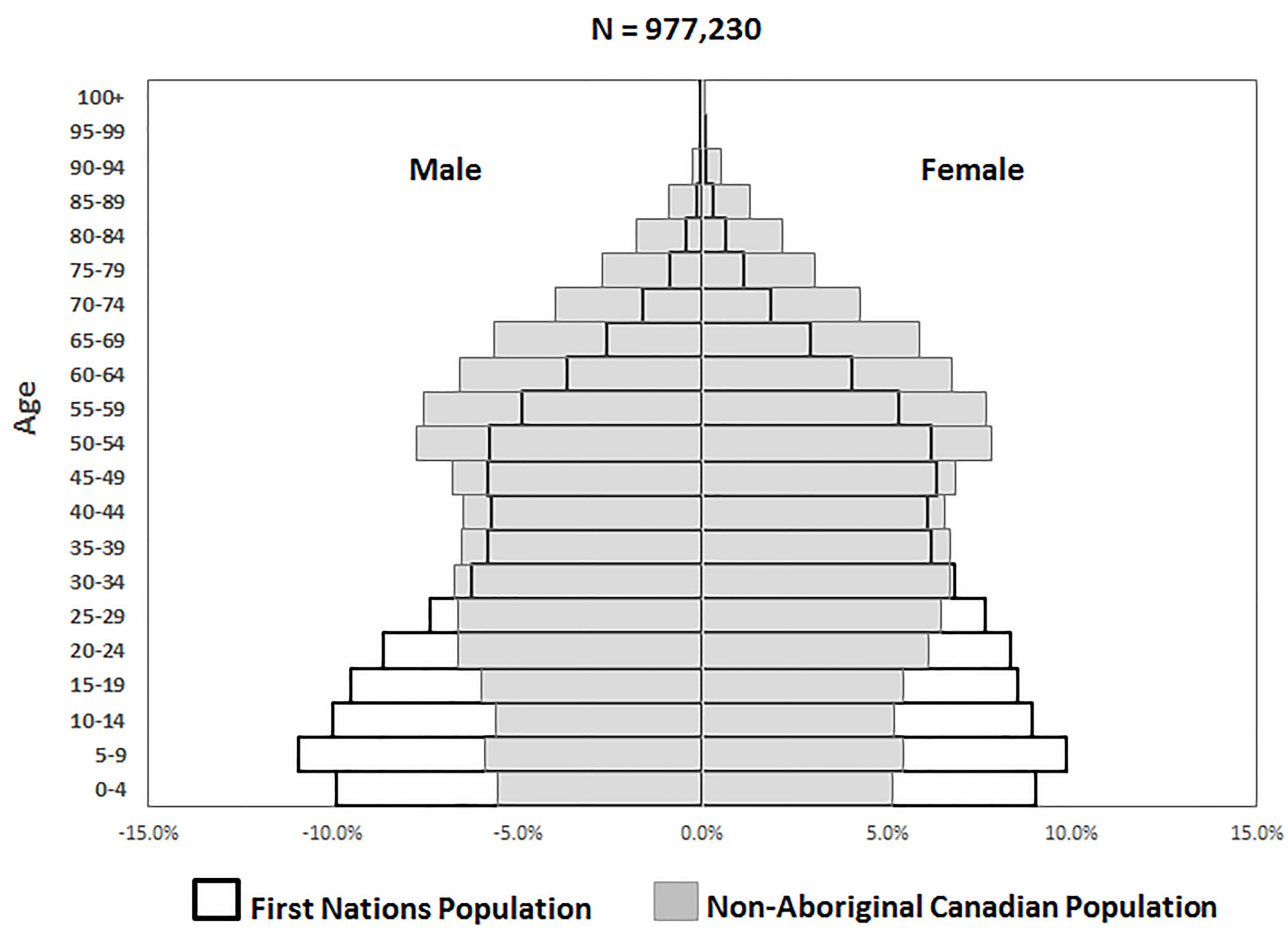

Fig. 3. Population Pyramid of the First Nations and non-Aboriginal Populations, Census 2016. This graph illustrates a population pyramid that compares the proportions, by sex and five-year age increments, of the First Nations and the non-Aboriginal Canadian populations in 2016. Source: Statistics Canada, Census of Population, 2016. First Nations Information Governance Centre tabulations, 2018.

There is a steadily increasing urbanization of First Nations peoples which can be attributed to factors such as mobility (education, employment, family needs), changes in self-reported identity, or demographic growth. The First Nations population is young in age and rapidly growing. Among status First Nations, the growth rate was higher for off-reserve $(+49.1$ percent $)$ in comparison to the on-reserve population $(+12.8$ percent) from 2006 to 2016 [24].

In 2016, the average age was 30.6 years, ten years younger than the general Canadian population (40.9 years). Figure 3 shows a population pyramid that compares the proportions, by sex and five-year age increments, of the First Nations and the non-Aboriginal Canadian populations in 2016 [27]. The age structure of the First Nations population is much younger than the rest of the non-Aboriginal Canadian population. One-third (29.2 percent) of the First Nations population were 14 years of age or younger, while 6.4 percent were 65 years of age and older [24]. This is in contrast to the aging Canadian population, where seniors outnumber children (16.9 percent vs 16.6 percent). From 2006 to 2016, the First Nations population rose by 39.3 percent [24]. In addition, 46.7 percent of individuals are under age 25 , compared to 28.4 percent for the rest of the Canadian population [24].
In 2016, women and girls accounted for 51.7 percent $(505,725)$ of the First Nations population compared to 48.2 percent $(471,510)$ for men and boys [28] Although First Nations children accounted for 4.9 percent of all children aged 0 to 4 , they accounted for 41.4 percent of all foster children in this age group who are living in private homes [29].

Language and culture are strong indicators of First Nations identity, resilience and overall well-being, at the individual and community levels. First Nations languages embody the histories, worldviews, and realities of First Nations peoples. In the past 20 years, communities have been moving towards revitalizing and preserving First Nations languages in Canada as an essential step to healing and Nation rebuilding. According to the 2016 Census, only 21.3 percent of First Nations people reported being able to have a conversation in an Aboriginal language [30]. According to Statistics Canada, ${ }^{3}$ nearly half (44.9 percent) of First Na-

\footnotetext{
${ }^{3}$ As discussed in the following sections, First Nations have long noted the reliability of many data sources including the Canadian Census and this is precisely why there has been a decades-long push for by First Nations, for First Nations data collection and analysis efforts.
} 
tions living on-reserve are able to speak an Aboriginal language compared with 13.4 percent of those living off-reserve [30]. Non-status First Nations people, who make up 23.8 percent of First Nations, are facing language loss with only 1.9 percent being able to converse in an Aboriginal language compared with 27.3 percent of status First Nations [30].

Housing and living conditions of First Nations peoples continues to be plagued by problems such as overcrowding, poor conditions, requiring major repairs, lack clean water, and lack of access to safe and affordable housing. In 2016, nearly one-quarter (24.2 percent) of First Nations peoples lived in a dwelling in need of major repairs [31]. Status First Nations living on-reserve were more likely than those living off-reserve to live in a dwelling in need of major repairs (44.2 percent vs. 14.2 percent) [31]. Status First Nations also experienced higher crowding conditions on-reserve (36.8 percent) than those living off-reserve (18.5 percent) [28]. According to the Assembly of First Nations (AFN), in March 2018 there were 81 long-term drinking water advisories in 56 First Nations communities affecting 45,000 citizens across Canada [32].

In general, First Nations people experience lower socio-economic status in comparison to the rest of Canadians. Many First Nations are faced with barriers such as high rates of poverty, unemployment, lower education, victimization, loss of culture and language, homelessness, lack of access to resources, poorer health, food insecurity, high incarceration rates, and high rates of suicides and intergenerational trauma. In 2015, the employment rate for First Nations people aged 25 to 54 was 62.4 percent, compared to 81.8 percent for non-Aboriginals [33]. The unemployment rate was more than double (13.2 percent) for First Nations aged 25 to 54 than for non-Aboriginal people (5.7 percent) [33]. First Nations aged 25 to 54 have lower rates for labour force participation (71.9 percent), compared to 86.7 percent for non-Aboriginal people [33].

The 2018 Spring Report of the Office of the Auditor General of Canada, which examined the socioeconomic gaps between on-reserve First Nations and other Canadians, revealed that the education gap is growing. It also indicated that on-reserve high school graduation rates of 1 in 2 reported by Indigenous Services Canada (ISC) may actually be closer to 1 in 4 [34]. According to Statistics Canada, in 2015, 47.1 percent of First Nations people completed postsecondary education, compared to 69.6 percent of nonAboriginal people. As a result of lower levels of ed- ucation attainment, First Nations people experienced higher unemployment and lower earnings, and were less likely to be employed in higher paying "knowledge occupations" as compared to non-Aboriginal people [33].

\section{Contemporary statistical context}

Multiple sources and systems of information and data on Aboriginal peoples have been created without much or any Aboriginal involvement or input, as many scholars have noted: "[D]ata collection efforts such as the census and broad reaching surveys were conducted with little input from Indigenous communities and peoples" [35]. Consequently, these existing data sources often provide a fragmented and incomplete picture of the realities of Aboriginal peoples in Canada.

Accessing current, quality data on First Nations peoples remains a complex issue with numerous challenges and considerations. Due to the variability in the collection and reporting of data, and the variance in the kinds of information collected regionally and nationally, it is difficult to access accurate, reliable, useful, and comparable data regarding First Nations peoples. First Nations require access to existing data to help inform their communities' planning and programs, however "[it] is not routinely used in planning and advocacy for the benefit of First Nation communities," leading many to ask why "meaningful, relevant, and useful data not been put into the hands of those who can use it?" [22].

Many First Nations experience arduous reporting requirements with regard to federal funding, however, resulting data collected are not being effectively analyzed and used to advance the well-being of First Nations. Data created and used to administer the Indian Act and federal programs are federal data. Though often collected by First Nations, they support federal programs. Further, more often than not, their quality is not high. And, as successive reports of the Auditor General of Canada have pointed out, the relevance of these data to communities is often not clear. Multiple reports are filed, but correspond little to community plans or priorities.

The 2018 Spring Report of the Auditor General of Canada reported on completed performance audits of government programs and activities, including two chapters specific to First Nation and Indigenous peoples: Socio-economic Gaps on First Nations Reserves 
Table 1

First Nations counts for Canada by sex, status, and type of residence, census of population, 2016

\begin{tabular}{|c|c|c|c|c|c|}
\hline & Total no. & Male & Female & On reserve and crown land ${ }^{1}$ & Off reserve ${ }^{1}$ \\
\hline Registered or treaty status ${ }^{1}$ & 744,850 & 358,645 & 386,210 & 329,340 & 415,510 \\
\hline Non-registered or treaty status ${ }^{1}$ & 232,380 & 112,860 & 119,515 & 5,040 & 227,335 \\
\hline Membership in a First Nation or Indian band ${ }^{2}$ & 792,140 & 381,105 & 411,030 & 332,675 & 459,460 \\
\hline Total $^{1}$ & 977,230 & 471,505 & 505,725 & 334,380 & 642,845 \\
\hline
\end{tabular}

Source: Statistics Canada, Census of Population, 2016. Note: Counts do not always add up perfectly due to rounding and differing population universes as noted below. ${ }^{1}$ Estimate based only on respondents who self-identified as First Nations; excludes those who did not. ${ }^{2}$ Users of the detailed First Nation and Indian band data from the 2016 Census should be aware that these data should not be used as official counts of First Nations and Indian bands in Canada. Users should refer to the individual First Nations or Indian bands for counts of their members.

examines Indigenous Services Canada (ISC) and Employment Training for Indigenous People - Employment and Social Development Canada (ESDC). Both chapters concluded that ISC and ESDC did not sufficiently use collected data, nor did they sufficiently measure or report whether their programs achieved their goals to close the socio-economic gaps [34]. The National Chief of the Assembly of First Nations, Perry Bellegarde, expressed concern that "Canada is requiring data and then not using it effectively to improve the lives of First Nations people" [36].

\subsection{Canadian census}

At present, the most recent statistical data on Canada's First Nations population is from 2016 and is derived from two main sources, each with its own limitations with regard to accuracy. The mandatory 2016 Census, administered by Canada's national statistical agency, Statistics Canada, is one main source of population data and captures the broadest range of First Nations ("North American Indian") identity definitions and thus gives the highest population estimate of 977 , 235 people with self-reported First Nations identity nationwide [37]. Table 1 shows the First Nations population counts from the 2016 census by sex, type of residence, status, and band membership, where such information is available [37,38].

Although the short form national census aimed to include all individuals who reside in occupied private dwellings in Canada, the long form census (also known as the National Household Survey, or NHS), from which enumeration of people with First Nations identity is derived, samples 25 percent of the population [39], therefore introducing sampling error into the results; however, this error is minimized due to the achievement of a 96.9 percent response rate [40]. Although the census is the only Statistics Canada instrument that collects data in First Nations communities and reserves, there were 14 such communities that were "incompletely enumerated" in 2016 , due to interruption of enumeration prior to completion or to denial of permission by community leadership to administer the census. These issues impact estimates of the First Nations identity population, the Registered or Treaty Indian population, the population who reported membership in a First Nation or Indian band, and the population living on Indian reserves and Indian settlements [39].

Additional questions in the long form census were asked to determine classification, with regard to Indian status, First Nation or Indian band membership, and residence on an Indian reserve or settlement. Of those identified as First Nations, 744,855 persons (76.2 percent) reported having registered or treaty Indian status [24], with Registered Indians defined as "persons who are registered under the Indian Act of Canada," and Treaty Indians defined as "persons who belong to a First Nation or Indian band that signed a treaty with the Crown" [37]. However, when considering the estimate based on the total sample of respondents who answered the status question (beyond those who identified as First Nations), 820,120 persons in Canada hold registered or treaty Indian status [37]. Respondents were instructed to exclude persons who had not registered under provisions of the Indian Act, even if they were entitled to do so [41].

Another distinct yet overlapping census classification is "Membership in a First Nation or Indian band," referring to whether a person is a member of "a body of Indians for whose collective use and benefit lands have been set apart or money is held by the Crown, or who have been declared to be a band for the purpose of the Indian Act" [42]. The 2016 Census estimates that 792,140 persons hold this classification [39]. Note that for this purpose "First Nation" and "Indian band" share the same definition and that the distinction in terminology reflects how certain First Nations choose to identify themselves. Statistics Canada also points out that it is not always necessary for a band member to be a Registered Indian, as many First Nations have exercised the right to establish their own membership code. 
Further, they note that due to the incomplete enumeration issue described above and the self-response nature of the census data, these may differ from First Nations' administrative data and should not be considered official estimates of membership counts [42]. As defined in the census, "On reserve" refers to Indian reserves and settlements, and all other areas are referred to as "Off reserve" [43].

\subsection{Indian Registration System}

The second main source of data on First Nations population counts is the Indian Registration System (IRS) maintained by Crown-Indigenous Relations and Northern Affairs Canada, formerly Indigenous and Northern Affairs Canada (INAC), which only includes registered status First Nations living on or off-reserve. Further, life event (i.e., births, deaths, migration between or off reserves or outside of Canada) data is updated by the bands with varying frequencies, meaning that the IRS numbers may not represent the true population at a given time [44]. As of December 31, 2017, the IRS included 987,520 registered First Nations individuals in 618 bands. It is important to note that the Indian Register does not distinguish between Indian Act reserves and lands affiliated to First Nations operating under Self-Government Agreements (SGAs).

Derived from the Indian Act, the IRS definition of a reserve is "a tract of land, the legal title to which is vested in Her Majesty that has been set apart by Her Majesty for the use and benefit of a band." To determine counts of registered individuals living on reserve and crown land, the Indian Register includes those who "reside on lands legally defined as Indian reserves, on Indian settlements usually represented by Crown Lands and on other lands affiliated to self-governing First Nations," while the off-reserve counts include "individuals affiliated to First Nations who may reside neither on reserve nor on Crown land according to the Indian Register" [44]. At December 31, 2017, there were 3,247 reserves, but not all are inhabited: of the registered First Nations population, 502,016 people were living on reserve and crown land and 478,504 were living off reserve. Table 2 shows the Registered First Nations population counts from the IRS, by sex and type of residence [45], and Table 3 shows the Registered First Nations population from the IRS by region [45].

Some of the main sources of statistical health data in Canada are under federal jurisdiction, and include: Census, vital registration, national health and so-
Table 2

Registered Indian population by sex and type of residence, December 31,2017

\begin{tabular}{lccc}
\hline & Total no. & Male & Female \\
\hline On reserve and crown land & 502,016 & 258,510 & 250,506 \\
Off reserve & 478,504 & 227,548 & 250,956 \\
Total & 987,520 & 486,058 & 501,462 \\
\hline
\end{tabular}

Source: Indigenous Services Canada/Crown Indigenous Relations and Northern Affairs Canada, Indian Registration System, December 31, 2017. Document prepared by: Statistics Team; Strategic Research and Statistics Directorate; Planning, Research and Statistics Branch; Chief Finances, Results and Delivery Officer (CFRDO) Sector, August 24, 2018.

Table 3

Registered Indian population for Canada by region, December 31, 2017

\begin{tabular}{lrc}
\hline & Total no. & Total (percent) \\
\hline Atlantic & 65,289 & 6.6 \\
Quebec & 88,967 & 9.0 \\
Ontario & 213,232 & 21.6 \\
Manitoba & 159,023 & 16.1 \\
Saskatchewan & 156,828 & 15.9 \\
Alberta & 128,351 & 13.0 \\
British Columbia & 146,952 & 14.9 \\
Yukon & 9,456 & 1.0 \\
Northwest Territories & 19,422 & 2.0 \\
Total (Canada) & 987,520 & 100.0 \\
\hline
\end{tabular}

Source: Indigenous Services Canada/Crown Indigenous Relations and Northern Affairs Canada, Indian Registration System, December 31, 2017. Document prepared by: Statistics Team; Strategic Research and Statistics Directorate; Planning, Research and Statistics Branch; Chief Finances, Results and Delivery Officer (CFRDO) Sector, August 24, 2018.

cial surveys, health services utilization records, and surveillance systems [46]. The Canadian Community Health Survey (CCHS), administered by Statistics Canada, collects information on the health status, health care system use and determinants of health of the Canadian population. The CCHS is not administered to First Nations peoples living on-reserve. Additionally, on-reserve First Nations are not included in the Aboriginal Peoples Survey (APS) - a national survey that collects social, economic, and cultural information of First Nations peoples living off-reserve. Coverage and data collection in Canadian government data initiatives/surveys is also a major challenge when considering different First Nations contexts/environments, such as on or off-reserve and status or non-status First Nations.

While the provinces and territories are responsible for the administration and delivery of health services to Canadians, the provision of health care services to First Nations is the responsibility of the federal government. The major sources of Canadian administrative health data are collected from provincial and territorial 
health agencies, such as vital statistics, disease surveillance registries, health care utilization, health insurance registries, and social surveys, and stored in a variety of health system databases. For instance, the Canadian Institute for Health Information (CIHI) manages multiple Canadian health databases and works with a broad range of partners to provide health data and information. Since Canadian health data have unique identifiers, records across different databases may be linked for research purposes. Together, these systems produce a vast amount of quality health information to be used for evidence-based decision-making to improve quality of care and patient health outcomes. For instance, the Health Insurance Registry captures demographic information of anyone who was alive and eligible to receive health care in the fiscal year. Status First Nations people are covered under the Non-Insured Health Benefits Program (which is transitioning from Health Canada's First Nations and Inuit Health Branch to Indigenous Services Canada) and receive health services and benefits that are not insured by provincial and territorial governments such as dental, vision care, prescription drugs, medical supplies, and medical transportation costs. However, First Nations still hold provincial and territorial health insurance and are included in the provincial and territorial health registries [47]. The Canadian Chronic Disease Surveillance System (CCDSS), administered by the Public Health Agency of Canada, uses linked administrative data from provincial and territorial surveillance systems, such as the Health Insurance Registry, to generate national estimates and trends on over 20 chronic diseases.

Researchers have identified the absence of ethnic identifiers at all levels as a key challenge to Indigenous coverage in health data systems [48]. This has been a longstanding oversight for many reasons, including Canada's emphasis on assimilation, the historic indifference to cultural specificity, and misuse of appropriate nomenclature. Concerns include the fact that "inconsistencies in First Nations, Inuit, and Métis ethnic identifiers in provincial health data collected through vital registration systems, hospital administrative datasets, and acute and chronic disease surveillance systems means that these populations are often invisible in health statistics" [48]. There is also a "systematic exclusion of subpopulations of First Nations people from health data initiatives according to place of residence or Indian Act grouping" [48]. Record linking provincial/territorial health datasets to First Nations registry lists provide a partial solution, however, the quality of the registration lists is potentially inaccurate and limited to First Nations that are registered [48]. Postal code has been used as a proxy, however, these are limited to areas where the large majority of the population is First Nations [48]. These large data gaps have made it more difficult to obtain a comprehensive, clear picture of the health status of First Nations in Canada.

In the past 20 years, there have been some significant advances in the First Nations health information environment. Progressive practices have been, and continue to be, identified that are assisting to fill in the First Nations patient identifier gaps of the health data initiatives and systems across Canada [49]. Some of initiatives to identify First Nations individuals in health database systems [49] include:

- Mustimuhw Community Electronic Medical Record: a community-based health information system for First Nations health centres that is designed and owned by First Nations (Cowichan Tribes) and reflects the needs and values of First Nations. The system respects the principles of OCAP $^{\circledR}$ (Ownership, Control, Access, and Possession) and is currently deployed in over 50 First Nations/sites in three provinces: British Columbia, Manitoba, and Saskatchewan.

- Ontario Cancer Registry/Indian Register Linkage (1968-2001): involved linking Ontario First Nations from the Indian Registry with provincial databases (Ontario Mortality Database and the Ontario Cancer Registry) to provide general population comparison data on cancer incidence, mortality and survival in First Nations.

- Unama'ki Client Registry (UCR) and Data Linkage Model: an anonymous electronic registry of five Unama'ki First Nations (Eskasoni, Membertou, Potlotek, Wagmatcook, and Waycobah) in Cape Breton - that involves the linkage First Nations, federal and provincial government administrative data to assist First Nations in their analysis and health planning.

- Newfoundland and Labrador Indigenous Administrative Data Identifier Standard: designed to "enable the records of Indigenous persons to be specifically identified, enabling users of data to more accurately plan, deliver, and measure the effectiveness of programs and services provided to Indigenous persons in Newfoundland and Labrador as well as monitor health outcomes" [50]. 


\subsection{First Nations regional health survey}

Under complete First Nations control, the First Nations Information Governance Centre (FNIGC), with its ten regional partners, designs and delivers unique data-gathering initiatives such as the First Nations Regional Health Survey (RHS), First Nations Early Childhood, Education and Employment Survey (FNREEES), First Nations Community Survey, and a new First Nations Labour and Employment Development Survey (FNLED), which provide an abundance of credible, culturally-relevant information about First Nations people living on reserve and in northern communities.

In existence since 1994, though originally envisioned as a longitudinal study, RHS is the only national health survey of First Nations living on reserve and in northern communities in Canada. The RHS is a crosssectional survey designed to measure the health, wellbeing, and social determinants of First Nations children (0-11 years), youth (12-17 years), and adults (18 years and over). Information gathered provides useful insight into timely issues and expands First Nations' knowledge of the strengths, resiliency, and conditions of First Nations. The RHS concluded its third phase of data collection in the fall 2016 and released a twovolume report in 2018.

The RHS provides unparalleled insight into a wide array of factors, from language and culture to healthcare access and food security, which affect the health and well-being of First Nations people. It collects and explores data related to health-care access, language, culture, nutrition, food security, physical activity, and personal and community wellness. In their evaluations of the RHS survey and processes, both the Harvard Project on American Indian Economic Development and the Johns Hopkins University Bloomberg School of Public Health recognized the RHS, an Indigenousled instrument to assess the health of Indigenous populations, as "a uniquely successful model worldwide" [51]. The high completion rates of the RHS and other surveys have made the FNIGC and its regional partners Canada's premier source of information about First Nations people living on reserve and in northern communities. The community-based delivery of successive survey cycles - as well as workshops, conferences, and training - have helped build community data governance and management capacity.

RHS surveys are typically conducted in the home using computer-assisted personal interviewing (CAPI). In Phase 3, the sampling frame was based on INAC
Indian Registry counts from 2014 of those living on reserve or on Crown land. Input and feedback were received from regional advisory committees, Regional Coordinators, regional data analysts, and key stakeholders. As part of the RHS Phase 3 development process, the questionnaire content of the previous phases of the RHS underwent extensive review and revisions. Comparability, non-response, and write-in answers were carefully assessed, and new themes were added to the core components based on extensive feedback. In many regions, survey questions were developed to address issues specific to First Nations people living within their respective region. Prior to deployment, the RHS undergoes an ethical independent review process to ensure its scientific and ethical acceptability.

\section{The reconciliation context}

The 2015 Summary of the Final Report of the Truth and Reconciliation Commission (TRC) of Canada highlighted that "better research and data are also required in order to monitor and develop strategies to reduce the overrepresentation of Aboriginal children in care" [52]. The report also noted that the federal government has failed to close the gap in health gap between Indigenous and non-Indigenous peoples. They "moved backwards" on Indigenous health by terminating funding to Aboriginal health organizations, including the Aboriginal Healing Foundation and the National Aboriginal Health Organization, which were "committed to models of research and treatment in which Aboriginal communities have ownership, control, access, and possession. Their loss significantly limits the development of accurate information about health issues and solutions under Aboriginal control" [52].

The TRC's 94 Calls to Action address the need for improved research and the development of measurable goals to close the health gaps experienced by Indigenous Peoples in Canada. Calls to Action 19 and 65, in particular, call upon the federal government to:

19. Establish [in consultation with Aboriginal peoples] measurable goals to identify and close the gaps in health outcomes between Aboriginal and non-Aboriginal communities, and to publish annual progress reports and assess long-term trends. Such efforts would focus on indicators such as: infant mortality, maternal health, suicide, mental health, addictions, life expectancy, birth rates, in- 
fant and child health issues, chronic diseases, illness and injury incidence, and the availability of appropriate health services.

65. Through the Social Sciences and Humanities Research Council, and in collaboration with Aboriginal peoples, post-secondary institutions and educators, and the National Centre for Truth and Reconciliation and its partner institutions ... establish a national research program with multi-year funding to advance understanding of reconciliation [53].

\section{First Nations data sovereignty}

Historically, in international contexts, the notion of "sovereignty" has held many different meanings and definitions. It has been understood to include various aspects of a nation's or state's recognized right and legitimacy to exercise authority over its affairs, a right to self-government, non-intervention, and freedom from interference in internal affairs. It also entails a responsibility to protect and ensure the wellbeing of its citizens [54]. A sovereign nation/state has the jurisdiction to govern, make laws, manage, control, and make decisions about their own peoples. With any sovereign authority also comes the right and responsibility to exercise jurisdiction in relation to information governance - to protect and govern all aspects of their citizens and nation's information and data. Data sovereignty means "managing information in a way that is consistent with the laws, practices and customs of the nation-state in which it is located" [55].

First Nations have an inherent and constitutionally protected right to self-government. This inherent right stems from sovereignty which existed prior to the arrival of European settlers. This includes jurisdiction over their education, laws, policies, health, and information. First Nations' rights are also supported by international instruments such as the UNDRIP [23]: "To understand the term sovereignty as Indian people interpret it one has to first understand, in the simplest of terms, the history of the settlement of this country and the Aboriginal/settler relations which evolved from the first moment of settlement by Europeans" [56].

As sovereign nations, First Nations have the right (inherent and constitutionally-protected) to exercise authority over their data and information. First Nations are accountable to their membership for the use and management of community information. The concept of data sovereignty “is linked with Indigenous peoples' right to maintain, control, protect and develop their cultural heritage, traditional knowledge and traditional cultural expressions, as well as their right to maintain, control, protect and develop their intellectual property over these" [23]. Data sovereignty is a crucial step toward realizing full self-government of First Nations.

The concept of Indigenous data sovereignty emerged in the late 20th century and has developed significantly. Through its work, FNIGC has given expression and practical meaning to the concept of First Nations data sovereignty as it relates to First Nations data and information. This reflects First Nations' desires and interests to govern and manage information in ways that are consistent with Nations' respective laws, practices, and customs. The US Indigenous Data Sovereignty Network defines Indigenous sovereignty as "the right of a nation to govern the collection, ownership, and application of its own data". It derives from tribes' inherent right to govern their peoples, lands, and resources. This conception of data sovereignty positions Indigenous nations' activities to govern data within an Indigenous rights framework" [57].

First Nations in Canada have an intimate relationship with and deep connection to their information, knowledge, and data, particularly traditional or sacred knowledge (teachings and ceremonial practices) that have been passed down from many generations to the next. This also applies to human biological data and Indigenous people's spiritual connection and cultural beliefs related to their DNA and genetic information. In Arizona, the Havasupai Tribe were successful in repatriating their genetic data and information following its authorized use in a research study, and celebrated through ceremony. In Canada, there is a strong movement to reclaim First Nation identities through control of information and the ability and authority to telling one's own stories with the data through an Indigenous lens. It has become clear that the next step is for First Nations citizens to rebuild their respective Nations and reclaim traditional systems by "building information governance capacity, enacting our own laws, entering into data sharing and licence-to-use contracts, creating regional data centres and repatriating our data, First Nations are getting closer to exercising full jurisdiction over our information" [23].

The British Columbia First Nations Data Governance Initiative (BCFNDGI), in their 2017 paper, "Decolonizing Data: Indigenous Data Sovereignty Primer," identified the shift in Nation-to-Nation relationships and the importance of recognizing how Indigenous data has traditionally been handled and managed by Canada. They write, "It is equally important to recog- 
nize that nation states have traditionally handled and managed Indigenous data in the following ways:

1. Methods and approaches used to gather, analyze and share data on Indigenous communities has reinforced systemic oppression, barriers and unequal power relations.

2. Data on Indigenous communities has typically been collected and interpreted through a lens of inherent lack, with a focus on statistics that reflect disadvantage and negative stereotyping.

3. Data on Indigenous communities collected by nation state institutions has been of little use to Indigenous communities, further distancing Nations from the information.

4. Data on Indigenous communities collected by the nation state government has been assumed to be owned and therefore controlled by said government; and,

5. With a lack of a meaningful Nation-to-Nation dialogue about data sovereignty [58].

In the $21^{\text {st }}$ Century, data is certainly one of the most sought-after resources. It has the potential to positively or negatively influence decision making, policy, and social change, and ultimately to transform nations. For decades, governments and scholars/researchers have been collecting, analyzing, and consuming vast amounts of First Nations data under the premise of making informed decisions, being accountable, and developing targeted policies and programs. Although their justifications can often appear sound, strictly Western methods and approaches used have reinforced systemic oppression, barriers, and unequal power relations between Western society and First Nations. This has led to countless laws, policies, and programs, created under the western worldviews/perspectives that are culturally distorted, discriminatory, oppressive, and harmful to First Nations.

The Western research paradigm has generally seen the majority of wealth, resources, and power held by government authorities and academic institutions and "First Nations have been the subject of too much irrelevant research, with the majority of research projects initiated by, paid for and carried out by nonIndigenous people from universities, government and industry" [23]. The resulting information and data have largely served the personal, professional, and/or corporate interests of non-First Nations scholars/researchers, rather than ensuring that First Nations governments and communities benefited.

The 1996 Report of the Royal Commission on Aboriginal Peoples noted that "Aboriginal people have not been consulted about what information should be collected, who should gather that information, who should maintain it, and who should have access to it" [59]. Instead, "Governments gather administrative and other data on First Nations often without their knowledge or consent and both they and researchers analyse, interpret and report on the data, often without consent, approval, review or input by First Nations representatives" [23]. There are many instances of First Nations people's data and knowledge being published by research teams without community approval or involvement in the analysis of the findings [22]. Without First Nations' involvement in the development and use of the data, communities have become resistant to sharing their information due to the mistrust in the data collection process. Without their participation, the overall quality of the data is questionable [22]. This resistance is a result of a history of exploitation and misuse of data and research in First Nations that has led non-First Nations parties to "pathologize [First Nations] and justify unnecessary government intervention" [22]. Building trusting relationships when doing research involving First Nations is fundamental to its success and legitimacy because "when communities do not trust the organizations collecting the data or the data collectors themselves, and are not invested in the purpose of the data, it becomes very difficult to garner participation" [22]. Furthermore, data on Indigenous communities has typically been collected and interpreted through a deficit lens, with a focus on statistics that reflect disadvantage and negative stereotyping. Without a genuine and clearly defined relationship, data collected and used is "subject to potential misinterpretation by researchers with different paradigms ... [which] can be used to present communities negatively without the context of historical trauma and Indigenous worldviews." [22].

Additional challenges to First Nations participation in research include a lack of involvement throughout the research processes; lack of engagement and relationship building; lack of access to capacity building and/or training; insufficient or non-existent funding or resources; misuse of information; lack of confidentiality; lack of informed consent; lack of transparency of benefits and risks; failure to reflect community priorities; research focuses that are not relevant to community; reports that sensationalize First Nations issues and result in stigmatization; the commercialization of traditional knowledge; and a lack of control or access to a community's information or data.

First Nations data, "when developed, gathered, and used correctly, provides First Nations with a way to 
bring evidence to issues that could have otherwise been ignored. When communities become their own data stewards, they can take on a leading role in the direction of their community wellbeing and in the very definition of that well-being" [22]. It is essential for research to "be integrated with cultural and traditional knowledge, such as Indigenous languages and history, so that the policy narrative is framed in a meaningful and relevant way" [35].

At present, "the ethics of this practice without appropriate consent from Indigenous governing bodies has been a challenge. Consequently, use of the information in the Indian Register now requires negotiation on a project by project basis" [60]. An important limitation of linking data from the Indian Registration System to provincial health databases is the lack of identification of non-status First Nations people as they are not listed in the Indian Registration System. Furthermore, these secondary data analyses do not typically describe any type of First Nations community engagement with respect to study design, interpretation, and dissemination. This becomes a "missed opportunity to support the shift towards research processes and outcomes that are relevant and useful to the communities whose data are being used" [46].

Historically, data on Indigenous communities collected by nation state institutions has been of little use to Indigenous communities, further distancing First Nations from their information. With different jurisdictions providing services based on First Nations status and residence (on or off-reserve), this poses a challenge. Differences in data collection between the federal government and the provinces and territories can prohibit comparability of data across, which is a barrier to generating an accurate national rate. It can also be a significant barrier to ensure that First nations can access the data, which is a drain on resources, including human resources, time, and funding [22]. Poor data quality remains an ongoing issue in many federal, provincial, and territorial government administrative databases or datasets as a result of missing cultural identifiers, inadequate sampling, and poor coverage $[37,48]$. Information that is collected may include Indigenous identity, however, these approaches "do not always ask to the level of detail required, lumping nonstatus First Nations, First Nations, Métis, and Inuit respondents together" [48]. First Nations may also be excluded from counts due to "place of residence and/or registration status as per Indian Act legislation [and as a result] the count is incomplete in its coverage of the Aboriginal population" [48]. First Nations access to data that affect them or that can be used in their planning often is generated "from different sources, and so may have different regional coverage and different ways of measuring variables so data cannot be compared across sources ... the multijurisdictional nature of accessing data can lead to barriers and delays for communities wishing to use the data" [22].

First Nations data sovereignty is an urgent priority and area of significant interest among Nations, leaders, policy makers, and community members as "global trends towards increasing the use of linked administrative datasets and "big data" risk further distancing already marginalized individuals and communities from active leadership and participation in the decision making regarding the use of their data" [46].

\subsection{First Nations-led approaches to data sovereignty}

First Nations' resistance to the unilateral, exploitative, or otherwise inadequate collection and use of information about them has been persistent over time. However, events in the early and mid-90s led First Nations leadership to assert control and build First Nations capacity for data collection, management, and dissemination in a concerted way. These efforts were driven by both practical responses to exclusionary Government of Canada data collection practices that threatened to compound existing socio-economic inequities, and an energized commitment to selfgovernance in the areas of research, education and stewardship of First Nations' information generally.

The first Regional Health Survey (RHS), then called the First Nations and Inuit Regional Longitudinal Health Survey or RHS pilot, took place in 1997 and involved First Nations and Inuit from across Canada. The impetus for the survey came in 1994 when several large longitudinal surveys were introduced for the Canadian population as a whole: the National Population Health Survey; the National Longitudinal Survey of Children and Youth (NLSCY); and the Survey of Labour and Income Dynamics. Collectively, these three surveys were designed to provide a wealth of information on health, child development, and labour market dynamics. However, none of them included First Nations peoples living on reserves and the number of off-reserve Aboriginal Peoples included was generally too small to permit reliable conclusions. The effect was to widen the gap between the amount of information available for the Canadian population in general and the amount available for Aboriginal groups. The RHS pilot in 1997 was implemented to address these deficiencies while ac- 
knowledging the need for First Nations and Inuit to control their own health information. It was the first national health survey in Canada to be carried out and controlled by First Nations and Inuit groups themselves" [61].

One of the greatest challenges for the RHS process was to balance:

- national and regional objectives;

- questions that would allow comparability with existing surveys and those adapted to the priorities of local communities; and

- control at the national and local community levels.

The solution was to approach the RHS not as a single national survey, but rather as a collection of regional surveys designed to provide a certain amount of national-level information. It allowed for regional priorities to be addressed and produced a feeling of ownership of the results and an interest in the findings. All of these things helped maximize use of the data - which was the fundamental objective of the survey [61].

As the First Nations Information Governance Committee, the antecedent to the current FNIGC, noted in 2004, officials from Health Canada and other ministries recognized the need to have comparable information for Aboriginal Peoples. In 1994, they hired John O'Neil of the Northern Health Studies Unit at the University of Manitoba to investigate the feasibility of developing a National Longitudinal Aboriginal Survey. O'Neil and his colleagues held a series of workshops across the country and consulted with about 150 Aboriginal technical staff working in the fields of health, child development, education, and economic development. The objective was to answer the question: "What kind of national longitudinal study would be acceptable to First Nation, Inuit and Métis people at the community level, while at the same time meeting the information needs of First Nations, Inuit and Métis organisations at the community, regional and national levels, and other levels of government?" [61].

Similarly, in 1999, the original First Nations and Inuit Regional Health Survey National Steering Committee had decided that the survey "should take the form of a group of regional surveys. The regional surveys were to be controlled and implemented by regional organizations. Late in 1995, the First Nations and Inuit political organizations in each region were invited to make a regional survey proposal. Each region found an organization or person to provide technical support to the survey and serve as Co-principal Inves- tigators. In each region a Regional Steering Committee was created to ensure that regional and local needs were met. Data from each of the regional surveys were compiled into a common database by staff at the University of Manitoba." [62].

The FNIGC evolved directly from the National Steering Committee (later the FNIG Committee, as above) of the original RHS. Formed in 1995 to implement the balanced regional-national strategy described above, the regionally-representative structure of the National Steering Committee was maintained when the FNIGC became an independent, incorporated entity in 2010. In addition to providing oversight and governance over the RHS, the FNIGC is also mandated by the AFN in Resolution no. 48/2009 to:

- promote, protect and advance the First Nations Ownership, Control, Access and Possession $\left(\mathrm{OCAP}^{\circledR}\right)$ principles, the inherent right to selfdetermination and jurisdiction in research and information management.

- build the research and information management capacity of First Nations, serve as a training centre, support knowledge transfer, act as a data repository and be the premier source of

- relevant, quality information and data on the social, health and wellness of First Nations which will serve to support policy development and informed decision making at all levels.

- seek and capitalize on funding opportunities that target First Nations information, research, training and data activities which can best be addressed through this First Nations driven and accountable organization ... [and]

- [in general] support the exercise of First Nations jurisdiction over information, their ability to obtain and use credible First Nations data to make informed decisions about the health, social wellness and impacts in First Nations communities and ... facilitate responsible and effective communications and information sharing based on that credible information [63].

Since its transformation from Committee to Centre, the FNIGC has expanded its quantitative research considerably. Operating to meet First Nations' data and information needs, as mandated by AFN resolutions originating from regional First Nations' decisionmaking bodies, FNIGC has added the FNREEES and FNLED survey to its core operations.

In terms of advancing First Nations' data sovereignty, these extensions of FNIGC's survey work perform multiple functions. Firstly, they demonstrate the con- 
siderable organizational capacity as First Nations organizations are developing as self-governing information units. FNIGC states that FNREEES was "the most technically complex survey ever undertaken by FNIGC, [and] a unique initiative, marking the first time this breadth of information had ever been collected in First Nations on-reserve and Northern communities" [64]. Secondly, the survey subject area marked a notable foray beyond the health paradigm and lent methodological credence to the argument for holistic approaches to well-being and development, which First Nations have made continuously. This holds true of both the FNREEES and FNLED. Thirdly, and not expectedly given the first two points, these surveys have opened possibilities for evidence-based research in the direct interest of First Nations, based on strengths not deficits. According to the FNIGC:

the 2016 FNREEES report showed strong associations between the importance First Nations people place on language, culture and family and the educational, employment, health and well-being outcomes in their communities. The FNREEES represents a rich source of information about life in First Nations communities, and it continues to support research, policy, programming, planning, knowledge-based decision-making, and program evaluation that serve the goal of improving social and economic well-being in First Nations communities [64].

In addition to the national RHS, FNREEES, and FNLED survey, First Nations are also independently pursuing several highly effective initiatives at the regional level. Examples include:

\section{The Tui'kn Partnership - A System for Health Information Management}

Tui' $\mathrm{kn}$ is a joint planning and collaboration platform on issues of mutual interest to the five First Nation communities on Cape Breton Island - Eskasoni, Membertou, Potlotek, Wagmatcook and Waycobah. Through carefully managed and legally stringent partnerships with district health authorities, the Nova Scotia Department of Health and Wellness, Health Canada, and Dalhousie University, the Tui'kn partners have been able to leverage external health information management resources while retaining ownership, access, and control over their communities' health data [65]. This collective community data has been an effective tool in improving community health services and policy.
Chiefs of Ontario and the Institute for Clinical Evaluative Sciences (ICES) - Data Governance Agreement

The Chiefs of Ontario (COO) is a coordinating body for 133 First Nations communities within the Province of Ontario. COO and the Institute for Clinical Evaluative Sciences (ICES) have a Data Governance Agreement that enables ICES to carry out health-related analyses for $\mathrm{COO}$ and the First Nations communities that $\mathrm{COO}$ supports and for whom it advocates.

Alberta First Nations Information Governance Centre

The Alberta First Nations Information Governance Centre (AFNIGC) is the FNIGC regional member representing what is now the province of Alberta, much of which includes the territory of First Nations of Numbered Treaties 6, 7, and 8. The AFINGC is a regional leader in OCAP ${ }^{\circledR}$ training, registering the most students in The Fundamentals of OCAP ${ }^{\circledR}$ online course on a monthly basis and providing regular communitybased, in-person training. AFNIGC has also created unique initiatives such as the First Nations Community Profiles. This process, managed and resourced by AFNIGC, enables individual First Nations to develop their own collective health and well-being profiles using a wide-range existing data which they could not access on their own [66].

\section{British Columbia First Nations Data Governance Initiative}

A leader in conceptualizing and realizing a resurgence of traditional Indigenous governance, the British Columbia First Nations Data Governance Initiative (BCFNDGI) takes a phased and considered approach to transformative change [58]. As of 2016, the BCFNDGI supported 13 First Nations communities from six distinct nations as:

First Nations Demonstration Sites [which] deploy a suite of locally developed First Nations program administration and data collection systems (e.g., Best Practices, Mustimuhw, Unification) across their Nations and provide advice to the Coordination Team on the development of data and information management standards and in the design of relevant community reports.

The BCFNDGI has also been remarkable for the breadth and quality of its analysis and guidelines for best practice in First Nations data sovereignty, favouring empowered and locally-specific interpretation rather than the development of templates. Another 
significant factor in its success is that a fundamental principle of the BCFNDGI is the fact that the federal and provincial governments with which it works recognize the First Nations as First Nations Governments, not just as stakeholders.

These First Nation-driven initiatives built in OCAP ${ }^{\circledR}$ principles from the outset, and are resulting in information systems and approaches to research that respect First Nations ownership and jurisdiction over information in innovative ways to meet the needs and develop the capacities of the First Nations involved [67].

\subsection{First Nations principles of Ownership, Control, Access, and Possession (OCAP $\left.{ }^{\circledR}\right)$}

What links all of these initiatives - national, regional and in between - are the integration and defence of the principles of $\mathrm{OCAP}^{\circledR}$. Since their establishment in 1998, the OCAP ${ }^{\circledR}$ principles have upheld First Nations rights over research that impacts them. OCAP ${ }^{\circledR}$ acknowledges and respects that the right of self-determination of First Nations includes the jurisdiction and authority to make decisions about research in their communities. It addresses issues of privacy, intellectual property, data custody and secondary use of data. OCAP ${ }^{\circledR}$ was conceived as a result of First Nations interest in protecting their data and information, the legacy of unethical research practices, and the desire to have control over research in their communities [68].

OCAP $^{\circledR}$ has also been described as "a political response to colonialism and the role of knowledge production in reproducing colonial relations." According to the report of the Royal Commission on Aboriginal Peoples:

The gathering of information and its subsequent use are inherently political. In the past, Aboriginal people have not been consulted about what information should be collected, who should gather that information, who should maintain it, and who should have access to it. The information gathered may or may not have been relevant to the questions, priorities and concerns of Aboriginal peoples. Because data gathering has frequently been imposed by outside authorities, it has met with resistance in many quarters. This is particularly true of the census, which is Canada's primary mechanism for gathering consistent information at regular intervals [59].
FNIGC plays a triple role here:

1. Its survey research and First Nations Data Centre embody $\mathrm{OCAP}^{\circledR}$ at its full implementation. Ownership, Access, Control, and Possession are assured through physical possession of the data, First Nations oversight of all stages of data collection, analysis, and storage, carefully maintained access protocols, and First Nations ownership of the data and secondary "intellectual properties."

2. It supports the efforts of its ten regional members in implementing OCAP ${ }^{\circledR}$ and advancing First Nations data sovereignty, and

3. It helps maintain stewardship (at the national level) of $\mathrm{OCAP}^{\circledR}$ outreach and training, including the management of The Fundamentals of OCAP online course [69].

OCAP $^{\circledR}$ is the de facto standard for conducting research on First Nations, and has grown to include the governance of First Nations information. Through the use of OCAP ${ }^{\circledR}$, First Nations leadership is able to assert sovereignty over and provide direction on how information can be used to benefit the community in a manner that mitigates any harm. Conversely, First Nations leadership is more accountable to their membership for the use and management of community information. The principles of OCAP ${ }^{\circledR}$ are:

Ownership: refers to the relationship of First Nations to their cultural knowledge, data, and information. This principle states that a community or group owns information collectively in the same way that an individual owns his or her personal information.

Control: affirms that First Nations, their communities, and representative bodies are within their rights in seeking to control over all aspects of research and information management processes that impact them. First Nations control of research can include all stages of a particular research projectfrom start to finish. The principle extends to the control of resources and review processes, the planning process, management of the information and so on.

Access: refers to the fact that First Nations must have access to information and data about themselves and their communities regardless of where it is held. The principle of access also refers to the right of First Nations communities and organizations to manage and make decisions regarding access to their collective information. This may be 
achieved, in practice, through standardized, formal protocols.

Possession: While ownership identifies the relationship between a people and their information in principle, possession or stewardship is more concrete: it refers to the physical control of data. Possession is the mechanism by which ownership can be asserted and protected [68].

To give practical expression to these principles and values in its own operations, the FNIGC also developed a set of governance and structural supports to ensure that data sovereignty was achieved and protected. These include the following:

1. Code of Research Ethics:

The RHS Code of Research Ethics provides a set of principles and procedures which guide the FNIGC in implementing the RHS on behalf of all First Nations. It also contains the First Nations Research Policy Statement:

- It is acknowledged and respected that the right of self-determination First Nations includes the jurisdiction to make decisions about research in their communities.

- The benefits to the communities, to each region and to the national effort should be strengthened by the research.

- Research should facilitate First Nation communities in learning more about the health and well being of their peoples, taking control and management of their health information and to assist in the promotion of healthy lifestyles, practices and effective program planning.

- The FNIGC promotes making the most of the funding opportunity on behalf of First Nations. We will reclaim the original foundations of our health and healing" [70].

2. Privacy impact assessments:

Policies and procedures regarding privacy and security have been implemented by the FNIGC survey management team and the First Nations Data Centre. The RHS is vigilant in the protection of personal privacy through the use of independent privacy impact assessments and maintaining the highest standards of personal privacy protection. Appropriate attention to personal privacy is commensurate with OCAP ${ }^{\circledR}$, which is the application of the collective privacy of the First $\mathrm{Na}$ tion [23].

3. Cultural framework:
Developed in 2005, the RHS Cultural Framework is a tool for moving from the prevailing and dominating worldview and moving towards First Nations self-determination over research and knowledge generated. FNIGC's RHS Cultural framework "reconciles a First Nation or Indigenous worldview with the need to collect data and conduct research. It presents a framework from which data on the health and wellbeing of First Nations can be collected, used and presented in a manner that is meaningful to First Nations peoples and communities" [23,71].

4. OCAP ${ }^{\circledR}$ trademark:

The FNIGC has a special role in advocacy and education involving $\mathrm{OCAP}^{\circledR}$. Immediately on incorporation, the board pursued the trademarking of $\mathrm{OCAP}^{\circledR}$ as a protective measure against misuse, misapplication or improper interpretation of what $\mathrm{OCAP}^{\circledR}$ actually means and how it is to be applied [23].

\subsection{National data governance strategy}

The need for relevant data and control was underscored in the 1996 Report on the Royal Commission on Aboriginal Peoples, which called for government support of Indigenous information management systems, including for infrastructure, training and capacity at the nation level. This priority is central to selfdetermination. Data created by and for First Nations reflect their goals, priorities, and worldviews rather than those of distant federal programs. Development of regional information governance capacity will have a solid foundation on which to build. For an entire generation, the FNIGC and its regional partners have tirelessly promoted the importance of relevant, high quality, accessible data created by and for First Nations.

There is mutual interest, from First Nations and the Government of Canada, in supporting First Nationsled institutions that are built from the ground up and mandated to serve First Nations governance at the nation level. As conceived by the FNIGC and its regional partner organizations, First Nations Regional Information Governance Centres (RIGCs) would be such institutions. These Centres would be First Nations-led, regionally-based data stewards and advisory centres that can support the information governance needs of First Nations governments and their service organizations in a way that enables them to realize their right to self-determination.

At their July 2016 Annual General Assembly, the AFN Chiefs-In Assembly agreed (Resolution no. 57/ 
2016) that Indigenous data sovereignty be recognized as "the cornerstone of nation-building" [72] and sought federal government funding and support to develop fully functional regional First Nations information governance centres across Canada, as well as coordination of a national First Nations data governance strategy. Further support for these notions and the FNIGC is found in Resolution no. 42/2018, wherein the Chiefs-in-Assembly state that they:

1. Assert that First Nations in Canada maintain ownership and control over data that relates to their identity, their people, language, history, culture, communities and Nations, both historic and contemporary, and that each Nation will establish regulations to govern their data, determining how it will be managed, accessed and shared with other governments, organizations and/or individuals.

2. Call on the First Nations Information Governance Centre (FNIGC) to coordinate, with support from the federal government, Statistics Canada, and the Assembly of First Nations, regional processes to engage First Nation Chiefs and leaders in each province and territory to discuss improving the quality of or access to data or statistical information related to their people and Nation.

3. Call on the Government of Canada to allocate funding to the First Nations Information Governance Centre (FNIGC) to align engagement processes related to First Nations data, statistics, and information management, and to expedite the development of First Nations' controlled Regional Information Governance Centres as part of the National First Nations Data Governance Strategy.

4. Assert that, in future, all federal, provincial, and territorial government investments in First Nations data governance and analysis, information management, statistics, and reporting must align with the objective of each First Nation achieving full data governance, building and maintaining across their government, the capacity to collect, store, protect, analyze, and utilize data in their decision-making and reporting, measuring their own progress towards the outcomes defined in their community development and nation rebuilding plans [73].

To help bring the RIGCs to realization, the FNIGC is working closely with its ten regional survey delivery partners. Each region is unique and at a different stage of development but all ten regions will be engaged in this work via the development of a National Data Governance Strategy, which will determine in part how they will inter-relate and come together to do nationallevel work, while respecting that the visions and goals of First Nations vary by community and region.

As with all work of the FNIGC and its regional partners, developing and establishing RIGCs will be guided by the First Nations principles of OCAP ${ }^{\circledR}$, which will be defined by each Nation through their expression of data sovereignty and the role of the RIGCs will be to further assist them in doing so. Consistent with the $\mathrm{OCAP}^{\circledR}$ principles themselves, the FNIGC and regional organizations adhere to free, prior and informed consent, respect for nation-to-nation relationships, and recognize the distinct customs of nations. The primary role of RIGCS will be to assist First Nations in collecting, holding, managing, and using their data in ways that will help inform and drive their selfdetermination.

FNIGC's vision is to see every First Nation achieve data sovereignty in alignment with its distinct worldview. The national and regional organizations work together to strengthen both data sovereignty and the development of governance and information systems at the community level.

By providing First Nations with $\mathrm{OCAP}^{\circledR}{ }^{\circledR}$-based training, advice and support, RIGCs can help communities realize the "power of data" to inform their decision-making. At the same time, they can help communities realize their own power to decide about data and information and to exercise the same sovereignty that other governments take for granted. This work is crucial in a context where government program structures continue to treat communities as mere administrators, collecting data on behalf of the government funder.

One obvious further function of RIGCs will be to support the data and research needs of First Nations regional service and political organizations in addition to First Nations communities. Yet there are other points of interaction as well. Where most major service sectors fall under provincial jurisdiction, First Nations must often interface with provincial or territorial systems to support their data needs. Although there is much variation in quality of relationships between First Nations and provincial governments, there are a growing number of tripartite or bilateral agreements with provinces and territories that entail dataor information-sharing agreements. At the same time, fully functioning RIGCs will be poised to help the fed- 
eral government measure progress on its commitments to support a transformed relationship with First Nations. Since November 2015, the federal government has made commitments on several fronts. Most notable among them are the commitments to implement the UNDRIP and the Calls to Action of the Truth and Reconciliation Commission; to develop a new fiscal relationship with First Nations featuring predictability, sufficiency and mutual accountability; to reduce the reporting burden; and to support the rebuilding of First Nations institutions and capacity.

For all these processes, there will be need for significant First Nations-led work to establish relevant, culturally-based indicators and to gather and share national-level statistics. Only such work can allow measurement of progress toward stated goals. Measuring progress will require Canada to enter into respectful information-sharing relationships with First Nations. Regional organizations could help mediate such relationships, as well as contribute their data, insights, and perspectives to national statistics-gathering processes led by the FNIGC.

\section{Conclusion}

In Canada, it is from the premise that First Nations are accountable to their citizens and to those that they serve for the use and management of community information that First Nations will exercise jurisdiction in relation to information governance. This authority is based on inherent and treaty rights supported by international instruments such as the United Nations Declaration on the Rights of Indigenous Peoples. This will require an ongoing examination of the issues of jurisdiction and the policies and procedures required by Nations to achieve data sovereignty, as well as careful consideration of the impacts data repatriation, and 'open government and open data' initiatives. By building information governance capacity, enacting First Nations laws, entering into data-sharing and licenceto-use contracts, creating regional data centres, and repatriating our data, First Nations are getting closer to exercising full jurisdiction over their information. As First Nations realize their own capacity to govern and use their information, the federal practice of "governing data on Indians" can give way to a nation-based approach. By supporting data governance within First Nations, the federal government will enhance its ability to base its reporting on sound planning, informed by solid evidence.

\section{Acknowledgments}

The First Nations Information Governance Centre (FNIGC) would like to acknowledge the following people as authors: Jonathan Dewar, PhD (Executive Director, FNIGC); Amy Nahwegahbow (Senior Research Advisor, FNIGC); Aaron Franks, PhD (Senior Manager, OCAP ${ }^{\circledR}$ and Information Governance, FNIGC); Alana Roscoe (Program Manager, Research and Development, FNIGC); and Angela MashfordPringle, PhD (Associate Director, Waakebiness-Bryce Institute for Indigenous Health, University of Toronto).

Special thanks also go to the following staff at the First Nations Information Governance Centre for research support: Albert Armieri (Senior Manager, Research and Information Management), Maria Santos (Program Manager, First Nations Data Centre), and Brad MacKay (Manager, Communications), for their research and editorial assistance in the preparation of this manuscript.

We would also like to thank Bonnie Healy (Chair of the Board of Directors, First Nations Information Governance Centre and Executive Director, Alberta First Nations Information Governance Centre); Gwen Phillips (Ktunaxa Nation, British Columbia First Nations Data Governance Initiative Champion); and Dr. Alexandra King, PhD (Cameco Chair in Indigenous Health, University of Saskatchewan) for their contributions and insights in reviewing the manuscript.

Finally, we are greatly appreciative to each of the FNIGC Regional Member Organizations and their teams who have dedicated their work to asserting data sovereignty and have worked tirelessly to create lasting change for the betterment of the First Nations peoples and communities in their respective regions.

\section{References}

[1] Dickason OP, McNab DT. Canada's First Nations: A History of Founding Peoples from Earliest Times. Toronto: Oxford University Press; 2009.

[2] Wabie BM. Aboriginal Women and Community Development: Consistency Across Time. [Internet]. A Thesis Submitted to the Committee on Graduate Studies in Partial Fulfilment of the Requirements for the Degree of Master of Arts in the Faculty of Arts and Science. Trent University; 1998 [cited 2018 Sept 18]. Available from: http://www.collectionscanada. gc.ca/obj/s4/f2/dsk2/ftp03/MQ40490.pdf.

[3] McGregor D, Bayha W, Simmons D. [Internet]. "Our Responsibility to Keep the Land Alive" Voices of Northern Indigenous Researchers. Pimatisiwin: A Journal of Aboriginal and Indigenous Community Health. 2010 [cited 2018 Sept 18]; 8(1): 101-123. Available from: http://citeseerx.ist.psu.edu/vie wdoc/download?doi=10.1.1.455.7354\&rep=rep1\&type=pdf. 
[4] Belanger Y. Ways of Knowing: An Introduction to Native Studies in Canada. Toronto: Nelson Publishing; 2013.

[5] Long D, Dickason OE. Visions of the Heart: Canadian Aboriginal Issues, 3rd Edition. Toronto: Oxford University Press; 2011.

[6] Waldram JB, Herring DA, Young TK. Aboriginal Health in Canada: Historical, Cultural and Epidemiological Perspectives; 2nd Edition. Toronto: University of Toronto Press; 2006.

[7] Boyer Y. Moving Aboriginal health Forward: Discarding Canada's Legal Barriers. Saskatoon, Saskatchewan: Purich Publishing Inc.; 2014. p. 223.

[8] Bell RA. Health Issues Facing the State's American Indian Populations. North Carolina Medical Journal. 2004; 65(6).

[9] DeJong DH. "If you knew the conditions": a chronicle of the Indian medical service and American Indian health care, 1908-1955. Lanham, MD: Lexington Books; 2008.

[10] Eschiti VS. Holistic approach to resolving American Indian/Alaska Native health care disparities. Journal of Holistic Nursing: Official Journal of the American Holistic Nurses' Association. 2004; 22(3): 201

[11] Jones DS. The Persistence of American Indian Health Disparities. American Journal of Public Health. 2006; 96(12): 212234.

[12] Kramer JM, Weller GR. North American Native Health: A Comparison Between Canada and the United States. Report No.: 0843-9885 Contract No.: Report. Thunder Bay, Ontario: Lakehead University; 1989.

[13] Weaver SM. Making Canadian Indian policy: the hidden agenda, 1968-1970. Toronto: University of Toronto Press; 1981

[14] Lavoie J, Forget E, Browne A. Caught at the Crossroad: First Nations Health Care and the Legacy of the Indian Act. Pimatisiwin: Journal of Aboriginal and Indigenous Community Health. 2010; 8(1): 83.

[15] Milloy J. Indian Act Colonialism: A Century of Dishonour, 1869-1969. 2008

[16] Barron FL, Waldram JB. The Indian Pass System in the Canadian West, 1882-1935. In: Barron FL, ed. 1885 and after: native society in transition. Regina, Saskatchewan: University of Regina; 1986. pp. 25-42.

[17] Cardinal H. The Unjust Society. 1969.

[18] Government of Canada. Statement by Prime Minister on release of the Final Report of the Truth and Reconciliation Commission. Ottawa; December 15, 2015 [cited 2018 Sept 19] Available at https://pm.gc.ca/eng/news/2015/12/15/statement -prime-minister-release-final-report-truth-and-reconciliationcommission.

[19] Palmater P. [Internet]. By buying Trans Mountain, the Trudeau government breaks an array of promises. Maclean's May 30, 2018 [cited 2018 Sept 18]. Available from: https:// www.macleans.ca/opinion/by-buying-trans-mountain-thetrudeau-government-breaks-an-array-of-promises/.

[20] Morgan J. [Internet]. Despite court setback, Ottawa vows to move forward on Trans Mountain pipeline. Financial Post. August 30, 2018 [cited 2018 Sept 18]. Available from: https://business.financialpost.com/commodities/energy/transmountain-pipeline-approval-quashed-by-court.

[21] King E, Pasernak S. Yellowhead Institute. A Special Report: Canada's Emerging Indigenous Rights Framework: A Critical Analysis. June 2018 [cited 2018 Sept 25]. Available from https://yellowheadinstitute.org/wp-content/uploads/2018/06/ yi-rights-report-june-2018-final-5.4.pdf.

[22] Alberta First Nations Information Governance Centre. Data
Resources and Challenges for First Nations Communities: Document Review and Position Paper. 2016.

[23] Taylor J, Kukutai T, eds. Indigenous Data Sovereignty: Toward an Agenda. Centre for Aboriginal Economic Policy Research (CAEPR). Research Monograph No. 38. (Features a chapter, "Pathways to First Nations' data and information sovereignty", authored by FNIGC). Australian National University Press. 2016.

[24] Statistics Canada. Aboriginal peoples in Canada: Key results from the 2016 Census. The Daily. Ottawa; October 25, 2017 [cited 2018 Sept 25]. Available from: https://www150.statcan. gc.ca/n1/daily-quotidien/171025/dq171025a-eng.htm.

[25] Indigenous and Northern Affairs Canada. Geomatics Services. Ottawa; November 2017 [cited 2018 Sept 25] Available from: https://www.aadnc-aandc.gc.ca/DAM/DAM-INTERHQ-AI/STAGING/texte-text/ai_mprm_fnc_tab_pdf_134496 5563974_eng.pdf.

[26] Statistics Canada. Census of Population 2016. Indigenous Services Canada/Crown and Indigenous Relations and Northern Affairs Canada, Strategic Research and Statistics Directorate tabulations, 2018

[27] Statistics Canada. Census of Population 2016. Ottawa.

[28] Statistics Canada. [Internet]. Aboriginal Population Profile, Catalogue no. 98-510-X2016001 (table). Data Tables, 2016 Census. July 18, 2018 [cited 2018 Sept 19]. Available from: http://www12.statcan.gc.ca/census-recensement/2016/dp-pd/ abpopprof/index.cfm?Lang=E

[29] Statistics Canada. Diverse family characteristics of Aboriginal children aged 0 to 4: Census of Population, 2016. Census In Brief. Ottawa; October 25, 2017.

[30] Statistics Canada. The Aboriginal languages of First Nations people, Métis and Inuit: Census of Population, 2016. Census In Brief. Ottawa; October 25, 2017.

[31] Statistics Canada. The housing conditions of Aboriginal people in Canada: Census of Population, 2016. Census In Brief. October 25, 2017

[32] Assembly of First Nations. [Internet]. AFN National Chief Perry Bellegarde on World Water Day 2018: "We Must Redouble Our Efforts to End all Drinking Water Advisories by 2021". March 22, 2018 [cited 2018 Sept 19]. Available from: https://www.afn.ca/2018/03/22/afn-national-chief-perry-belle garde-world-water-day-2018-must-redouble-efforts-end-drin king-water-advisories-2021/.

[33] Moyser M. Aboriginal People Living Off-Reserve and the Labour Market: Estimates from the Labour Force Survey, 2007-2015. Statistics Canada. Ottawa; March 2017 [cited 2018 Sept 18]. Available from: https://www150.statcan.gc.ca/ n1/pub/71-588-x/71-588-x2017001-eng.htm.

[34] Office of the Auditor General of Canada. 2018 Spring Reports of the Auditor General of Canada to the Parliament of Canada. Report 5 - Socio-economic Gaps on First Nations Reserves Indigenous Services Canada. Ottawa; 2018 [cited 2018 Sept 18]. Available from: http://www.oag-bvg.gc.ca/internet/Eng lish/parl_oag_201805_05_e_43037.html

[35] Steffler J. The Indigenous Data Landscape in Canada: An Overview. Aboriginal Policy Studies. 2016; 5(2), 149-164. p. 151.

[36] Assembly of First Nations. [Internet]. Auditor General Report Shows Need for Government to Make Better Use of Data Work with First Nations to Make Faster Progress on Closing the Gap. May 29, 2018 [cited 2018 Sept 18]. Available from: https://www.afn.ca/2018/05/30/auditor-general-reportshows-need-government-make-better-use-data-work-firstnations-make-faster-progress-closing-gap-2/. 
[37] Statistics Canada. [Internet]. Aboriginal Identity (9), Dwelling Condition (4), Registered or Treaty Indian Status (3), Residence by Aboriginal Geography (10), Age (12) and Sex (3) for the Population in Private Households, Catalogue no. 98-400-X2016164 (table). Data Tables, 2016 Census. [cited 2018 Sept 18]. Available from: https://www12.statcan. gc.ca/census-recensement/2016/dp-pd/dt-td/Lp-eng.cfm?LA $\mathrm{NG}=\mathrm{E} \& \mathrm{APATH}=3 \& \mathrm{DETAIL}=0 \& \mathrm{DIM}=0 \& \mathrm{FL}=\mathrm{A} \& \mathrm{FREE}=$ $0 \& \mathrm{GC}=0 \& \mathrm{GID}=0 \& \mathrm{GK}=0 \& \mathrm{GRP}=1 \& \mathrm{PID}=0 \& \mathrm{PRID}=10 \& \mathrm{P}$ TYPE $=109445 \& S=0 \&$ SHOWALL $=0 \& S U B=0 \&$ Temporal $=$ $2017 \&$ THEME $=122 \&$ VID $=0 \&$ VNAMEE $=\&$ VNAMEF.

[38] Statistics Canada. [Internet]. Membership in a First Nation or Indian Band (663), Residence on or off Reserve (3), Age (10B) and Sex (3) for the Population in Private Households, Catalogue no. 98-400-X2016393 (table). Data Tables, 2016 Census. [cited 2018 Sept 18]. Available from: https://www12. statcan.gc.ca/census-recensement/2016/dp-pd/dt-td/Lp-eng. $\mathrm{cfm}$ ?LANG $=\mathrm{E} \& \mathrm{APATH}=3 \& \mathrm{DETAIL}=0 \& \mathrm{DIM}=0 \& \mathrm{FL}=\mathrm{A} \&$ $\mathrm{FREE}=0 \& \mathrm{GC}=0 \& \mathrm{GID}=0 \& \mathrm{GK}=0 \& \mathrm{GRP}=1 \& \mathrm{PID}=0 \& \mathrm{PRID}=$ $10 \& \mathrm{PTYPE}=109445 \& \mathrm{~S}=0 \&$ SHOWALL $=0 \& \mathrm{SUB}=0 \&$ Temp oral $=2017 \&$ THEME $=122 \& \mathrm{VID}=0 \& \mathrm{VNAMEE}=\& \mathrm{VNAM}$ EF.

[39] Statistics Canada. Aboriginal Peoples Reference Guide: Census of Population, 2016. Census In Brief. October 25, 2017 [cited 2018 Sept 18]. Available from: https://www12.statcan. gc.ca/census-recensement/2016/ref/guides/009/98-500-x201 6009-eng.cfm.

[40] Statistics Canada. Guide to the Census of Population, 2016: Chapter 10 - Data quality assessment. 2017 [cited 2018 Sept 18]. Available from: https://www12.statcan.gc.ca/census-rece nsement/2016/ref/98-304/chap10-eng.cfm\#a5.

[41] Statistics Canada. [Internet]. Dictionary, Census of Population, 2016: Registered or Treaty Indian status. 2016 [cited 2018 Sept 18]. Available from: https://www12.statcan.gc.ca/ census-recensement/2016/ref/dict/pop116-eng.cfm.

[42] Statistics Canada. [Internet]. Dictionary, Census of Population, 2016: Membership in a First Nation or Indian band. 2017 [cited 2018 Sept 18]. Available from: https://www12.statcan. gc.ca/census-recensement/2016/ref/dict/pop070-eng.cfm.

[43] Statistics Canada. [Internet]. Census Program Reference materials, 2011: Concepts and variables - Aboriginal Peoples Technical Report. 2015 [cited 2018 Sept 18]. Available from: https://www12.statcan.gc.ca/nhs-enm/2011/ref/reportsrapports/ap-pa/ch1-eng.cfm\#A_3_1.

[44] Indigenous and Northern Affairs Canada. [Internet]. Registered Indian Population by Sex and Residence 2016. 2018 [cited 2018 Sept 18]. Available from: https://www.aadncaandc.gc.ca/eng/1523286391452/1523286414623.

[45] Indigenous Services Canada/Crown Indigenous Relations and Northern Affairs Canada, Indian Registration System. December 31, 2017.

[46] Smylie J, Firestone M. Back to the basics: Identifying and addressing underlying challenges in achieving high quality and relevant health statistics for indigenous populations in Canada. Stat J IAOS. 2015; 31(1): 67-87. doi: 10.3233/SJI150864.

[47] Ellison J, et al. Estimating chronic disease rates in Canada: which population-wide denominator to use? Health Promot Chronic Dis Prev Can. October 2016; 36(10): 224-230. [cited 2018 Sept 25]. Available from: https://www.ncbi.nlm.nih.gov /pmc/articles/PMC5158125/.

[48] Smylie J. Achieving Strength through Numbers: First Nations, Inuit, and Métis Health Information. National Collaborating Centre for Aboriginal Health. 2009-2010 [cited 2018
Sept 18]. Available at: http://www.welllivinghouse.com/wpcontent/uploads/2014/04/Achieving-strength-thru-numbers1. pdf.

[49] Canadian Partnership Against Cancer. First Nations, Inuit and Métis Action Plan on Cancer Control: Environmental scan and analysis of existing patient identification systems for First Nations, Inuit and Métis peoples. Final Report. March 2012 [cited 2018 Sept 25]. Available from: http://content.cancervie w.ca/download/cv/fnim/documents/fnimpatientidsystemspdf.

[50] Department of Health and Community Services Newfoundland and Labrador Centre for Health Information. Newfoundland and Labrador Indigenous Administrative Data Identifier Standard. December 2017 [cited 2018 Sept 25]. Available from: https://www.nlchi.nl.ca/images/NL_Indigenous_Admi nistrative_Data_Identifier_Standard_FINAL_2017-12-12. pdf.

[51] Kristin Mmari, Nan Astone, Robert Blum, Deana Around Him, "Review of RHS 2 (2008-2010), Bloomberg School of Public Health, Johns Hopkins University, 4; Harvard Project on American Indian Economic Development, "Review of the First Nations Regional Longitudinal Health Survey (RHS) 2002/2003," April 2006, iv.

[52] Truth and Reconciliation Commission of Canada. Honouring the truth, reconciling for the future: Summary of the final report of the Truth and Reconciliation Commission of Canada. Ottawa; 2015.

[53] Truth and Reconciliation Commission of Canada. Truth and Reconciliation Commission of Canada: Calls to action. Winnipeg, Manitoba; 2015.

[54] Glanville L. The antecedents of 'sovereignty as responsibility'. European Journal of International Relations. 2010; 17(2): 233-255. DOI: 10.1177/1354066109346889.

[55] Taylor J, Kukutai T. eds. Indigenous Data Sovereignty: Toward an Agenda. Centre for Aboriginal Economic Policy Research (CAEPR). Research Monograph No. 38. (Features a chapter, "What does data sovereignty imply: what does it look like?", authored by C Matthew Snipp). Australian National University Press; 2016.

[56] LaForme HS. Indian Sovereignty: What Does It Mean? Canadian Journal of Native Studies, XI, 2, 1991: 253-266. [cited 2018 Sept 25]. Available at: http://www3.brandonu.ca/cjns/ 11.2/laforme.pdf.

[57] US Indigenous Data Sovereignty Network [Internet]. Defining Indigenous Data Sovereignty. [cited 2018 Sept 18]. Available at: https://usindigenousdata.arizona.edu/about-us-0.

[58] British Columbia First Nations' Data Governance Initiative (BCFNDGI). Decolonizing Data: Indigenous Data Sovereignty Primer. Prepared by Open North. April 2017.

[59] Royal Commission on Aboriginal Peoples. Report of the Royal Commission on Aboriginal Peoples (RCAP): Volume 3 - Gathering Strength. Ottawa; 1996. [cited 2018 Sept 19]. Available from: http://data2.archives.ca/e/e448/e01118823003.pdf.

[60] Anderson M, Smylie J, Anderson I, Sinclair R, Crengle S. First Nations, Métis, and Inuit Health Indicators in Canada A Background Paper for the project "Action Oriented Indicators of Health and Health Systems Development for Indigenous Peoples in Australia, Canada, and New Zealand". 2006 [cited 2018 Sept 19]. Available at: http://www.med.uottawa.ca/sim/ data/Images/Aboriginal_health_indicators.pdf.

[61] First Nations Information Governance Committee. First Nations and Inuit Regional Health Surveys, 1997: A Synthesis of the National and Regional Reports. First Nations Centre at the National Aboriginal Health Organization. Ottawa; 2004. 
[62] First Nations and Inuit Regional Health Survey National Steering Committee. Final Report: First Nations and Inuit Regional Health Survey. Ottawa; January 1999.

[63] Assembly of First Nations. Resolution No. 48/2009, Ottawa; December 2009.

[64] First Nations Information Governance Centre. First Nations Regional Early Childhood, Education and Employment Survey. [cited 2018 Sept 25]. Available from: https://fnigc.ca/ first-nations-regional-early-childhood-education-and-employ ment-survey.html.

[65] Tui'kn Partnership. About Tui'kn. [Internet]. [cited 2018 Sept 25]. Available from: http://www.tuikn.ca/about-tuikn/.

[66] Alberta First Nations Information Governance Centre. $\mathrm{OCAP}^{\circledR}$ \& $\mathrm{OCAP}^{\circledR}$ in Action. [cited 2018 Sept 25]. Available from: http://www.afnigc.ca/main/includes/media/pdf/ community percent20resources/(New) percent20AFNIGC percent20OCAP percent20Presentation percent20October percent202017.pdf.

[67] First Nations Information Governance Centre. Ownership, Control, Access and Possession $\left(\mathrm{OCAP}^{\mathrm{TM}}\right)$ : The Path to First Nations Information Governance. Ottawa; May 2014.

[68] First Nations Information Governance Centre (Formerly Committee). First Nations Regional Longitudinal Health Survey (RHS) Code of Research Ethics. Ottawa; [updated 2007 Feb 22].
[69] First Nations Information Governance Centre. [Internet] FNIGC Training: Fundamentals of OCAP ${ }^{\circledR}$ [cited 2018 Dec 21]. Available from: https://fnigc.ca/training/fundamentalsocap.html.

[70] First Nations Information Governance Centre. [Internet]. About RHS. [cited 2018 Sept 25]. Available from: https:// fnigc.ca/our-work/regional-health-survey/about-rhs.html.

[71] First Nations Information Governance Centre (Formerly Committee). First Nations Regional Longitudinal Health Survey (RHS) Cultural Framework. Ottawa; 2005.

[72] Assembly of First Nations. [Internet]. Resolution No. 57/2016: Funding for Regional First Nations Information Government Centres. Ottawa; 2016. [cited 2018 Sept 19] Available from: https://www.afn.ca/uploads/files/resolutions/ 2016_aga_res.pdf.

[73] Assembly of First Nations. [Internet]. Resolution No 42/2018: Data Sovereignty. Ottawa; 2018. [cited $2018 \mathrm{Dec}$ 21]. Available from: https://www.afn.ca/wp-content/uploads/ 2018/08/2018_Resolutions_ENG.pdf. 